\title{
A novel open synovectomy technique using an arthroscopy shaver blade in revision surgery to treat infected total knee arthroplasty: a technical note
}

\author{
Oog-Jin Shon ${ }^{1,2}$, In Jun Lee ${ }^{2}$ and Gi Beom Kim ${ }^{1,2^{*}}$ (D)
}

\begin{abstract}
Background: This article introduces a novel open synovectomy technique using an arthroscopy shaver blade to effectively remove intra-articular synovitis during revision surgery for infected primary total knee arthroplasty.

Methods (techniques): Open synovectomy is performed using a 4.2- $\mathrm{mm}$ arthroscopy shaver blade, and the handpiece is connected to suction drainage. Suction is supplied through the central cylinder of the shaver blade to bring the debrided fragments of soft tissue into the window. Grossly inflamed, reddened, diseased synovium is debrided to reveal yellowish, healthy synovium. The inflamed tissues of the knee joint (suprapatellar pouch, medial and lateral gutters, and peripatellar area) are debrided. Then, with maintaining full flexion of the knee joint, a shaver equipped with a longer bar can be used to easily access the medial and lateral posterior compartments, which are generally difficult to access.
\end{abstract}

Results: During a mean of 13.5-month follow-up, there was no recurrent infection in either group; however, patients who underwent the novel technique improved significantly faster in terms of acute serological markers during the first period.

Conclusions: This technique yielded favorable outcomes compared with the conventional technique. In particular, it may facilitate the approach to the posterior joint space, which is difficult to access.

Keywords: Infected total knee arthroplasty, Second-stage revision surgery, Synovectomy, Arthroscopic shaver blade

\section{Introduction}

The number of total knee arthroplasties (TKAs) has increased with the growing elderly population, which has inevitably resulted in a corresponding increase in the prevalence of postoperative infection $[1,2]$. Infection following TKA is a serious condition that can lead to many complications, and its management is often challenging

\footnotetext{
*Correspondence: donggamgb@hanmail.net

${ }^{1}$ Present Address: Department of Orthopedic Surgery, Yeungnam

University College of Medicine, 170 Hyeonchung-ro Nam-gu, Daegu 42415, Republic of Korea

Full list of author information is available at the end of the article
}

[3-5]. Despite advances in diagnostic tools and treatment strategies, the annual infection rate associated with primary TKA has been reported to be approximately $0.6-$ $2 \%[6,7]$.

Infection following TKA is often accompanied by synovitis, and a specific pattern of synovitis has been reported to be a characteristic sign of infected TKA [8-10]. Although specific treatment strategies may differ depending on the type and causative microorganism of infection [11-13], synovectomy is an essential surgical procedure in most revision surgeries. However, there is a

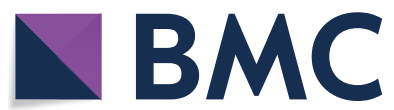

(c) The Author(s) 2022. Open Access This article is licensed under a Creative Commons Attribution 4.0 International License, which permits use, sharing, adaptation, distribution and reproduction in any medium or format, as long as you give appropriate credit to the original author(s) and the source, provide a link to the Creative Commons licence, and indicate if changes were made. The images or other third party material in this article are included in the article's Creative Commons licence, unless indicated otherwise in a credit line to the material. If material is not included in the article's Creative Commons licence and your intended use is not permitted by statutory regulation or exceeds the permitted use, you will need to obtain permission directly from the copyright holder. To view a copy of this licence, visit http://creativecommons.org/licenses/by/4.0/. The Creative Commons Public Domain Dedication waiver (http://creativeco mmons.org/publicdomain/zero/1.0/) applies to the data made available in this article, unless otherwise stated in a credit line to the data. 
paucity of published studies describing detailed synovectomy techniques.

To our knowledge, most surgeons perform synovectomy using conventional surgical instruments such as a rongeur, electric cautery, and surgical blades during revision surgeries for infected TKA. However, there are no dedicated instruments to effectively remove infected synovium. Moreover, conventional techniques have major limitations, including incomplete removal of contaminated tissue, bleeding due to excessive removal of tissue, and difficulty in approaching the narrow space in the joint. Therefore, we describe a novel open synovectomy technique using an arthroscopy shaver blade to effectively treat intra-articular synovitis in second-stage revision surgery to treat infected primary TKA.

\section{Surgical technique}

\section{Open synovectomy technique using a shaver blade}

The patient is positioned supine on the operating table. The joint is exposed through conventional medial parapatellar arthrotomy. After removing pre-existing TKA components, synovectomy is performed. A 4.2-mm arthroscopy shaver blade (UltraFRR, CONMED, Largo, FL USA), powered by an arthroscopic power console, is assembled, and the handpiece is connected to suction drainage. Suction is supplied through the central cylinder of the shaver blade to bring the debrided fragments of soft tissue into the window. As the shaver blade rotates, the debrided tissue is aspirated through the central tube and collected in a suction trap (Fig. 1A). Unlike arthroscopic surgery, there is no need for a connection to an irrigation pump. After setting the speed to approximately 1800-3000 rpm, the surgeon can toggle between oscillating and forward modes. The shaver can be operated using its own buttons or pedals, as in arthroscopic surgery. During the shaving process, the assistant manually provides saline solution using an irrigation spoid (Fig. 1B).

With direct visualization, the arthroscopy shaver blade is placed on the diseased synovial lining throughout the joint. Grossly inflamed, reddened, diseased synovium is debrided to reveal yellowish, healthy synovium. Anterior synovectomy is performed starting in the suprapatellar pouch (Fig. 2A, B). The medial and lateral gutters are then visualized, and the synovitis is debrided (Fig. 2C, D; Additional file 1: Video S1). While assistants maintain full flexion and traction of the knee joint, a shaver equipped with a longer bar can be used to easily access the medial and lateral posterior compartments, which are generally difficult to access (Fig. 2E-G). Finally, the inflamed soft tissues of the peripatellar area are debrided using the shaver (Fig. 3; Additional file 1: Video S1).

\section{Revision surgery and postoperative management}

For all cases in second-stage revision TKA, the first surgery is performed using an antibiotic-loaded articulating cement spacer. A single closed suction drain is inserted and is removed 3-7 days postoperatively. A knee immobilizer is applied to the knee at maximum extension. After drain removal, range of motion of the knee joint is permitted if pain subsides. One week postoperatively, partial weight-bearing with crutches is permitted. All patients undergo a 6-week course of organism-sensitive antibiotic therapy in consultation with an infectious disease specialist. Laboratory investigations, including serum white blood cell (WBC) count, erythrocyte sedimentation rate
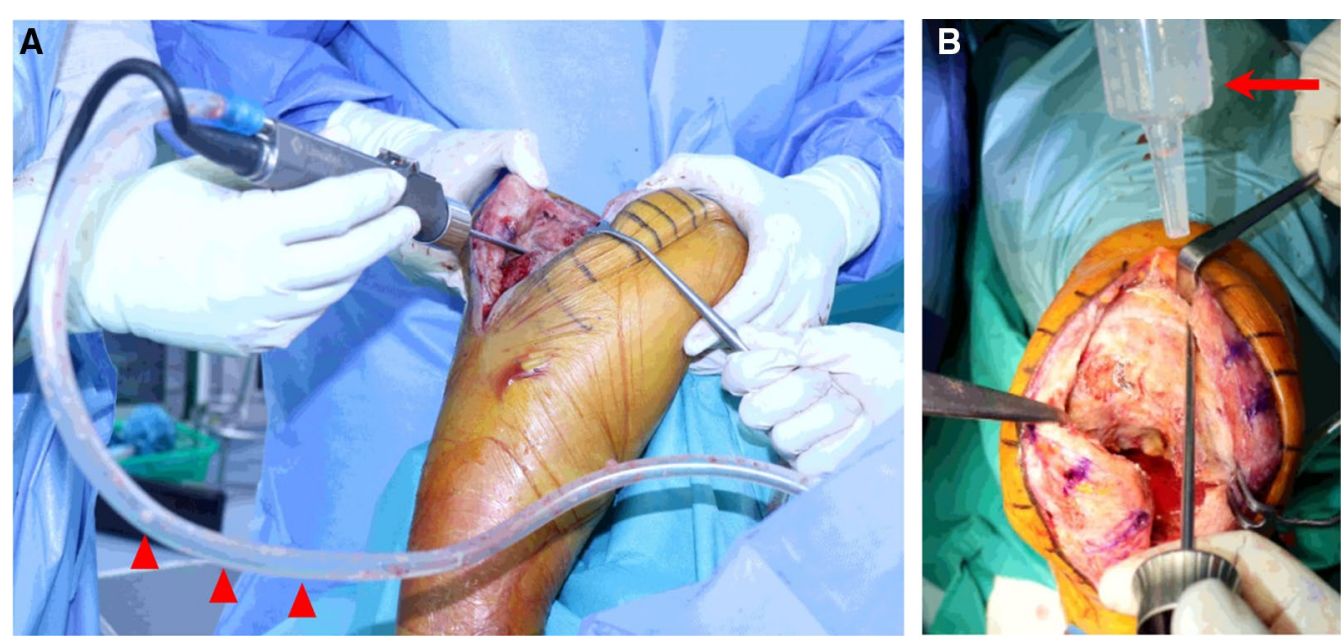

Fig. 1 Basic supplementary preparations. A As the shaver blade rotates, the debrided tissue is aspirated through the central tube and collected in a suction trap (red-headed arrow). B During the shaving process, the assistant manually provides saline solution using an irrigation spoid (red arrow) 

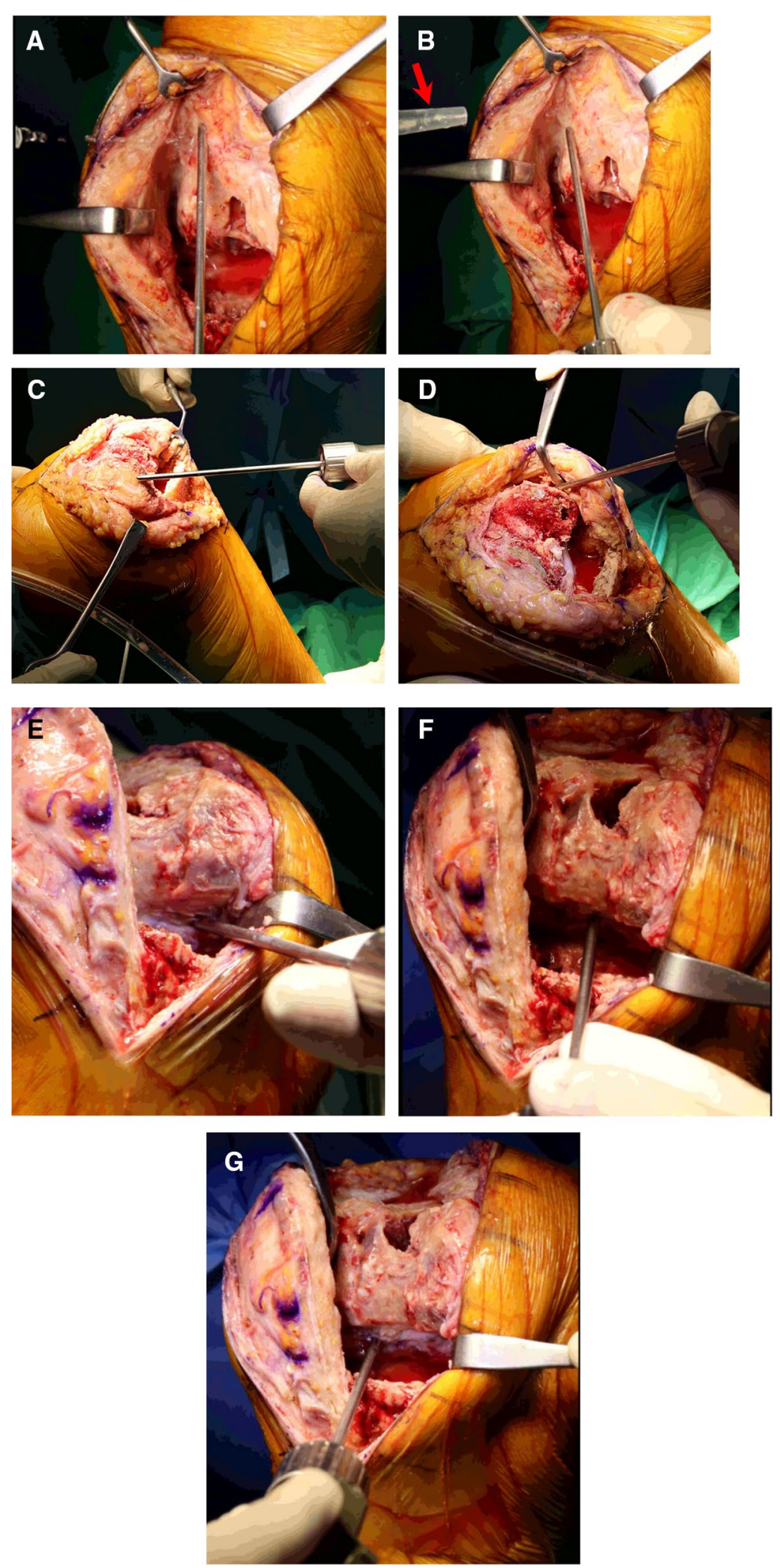

Fig. 2 Detailed shaving process. A, B Anterior synovectomy is performed starting in the suprapatellar pouch. C, D The medial and lateral gutters are then visualized, and the synovitis is debrided. $\mathbf{E}, \mathbf{F}, \mathbf{G}$ With the knee joint in full flexion by the assistant, a shaver with a longer bar can be used to easily access the medial and lateral posterior compartments, which are generally difficult to access 

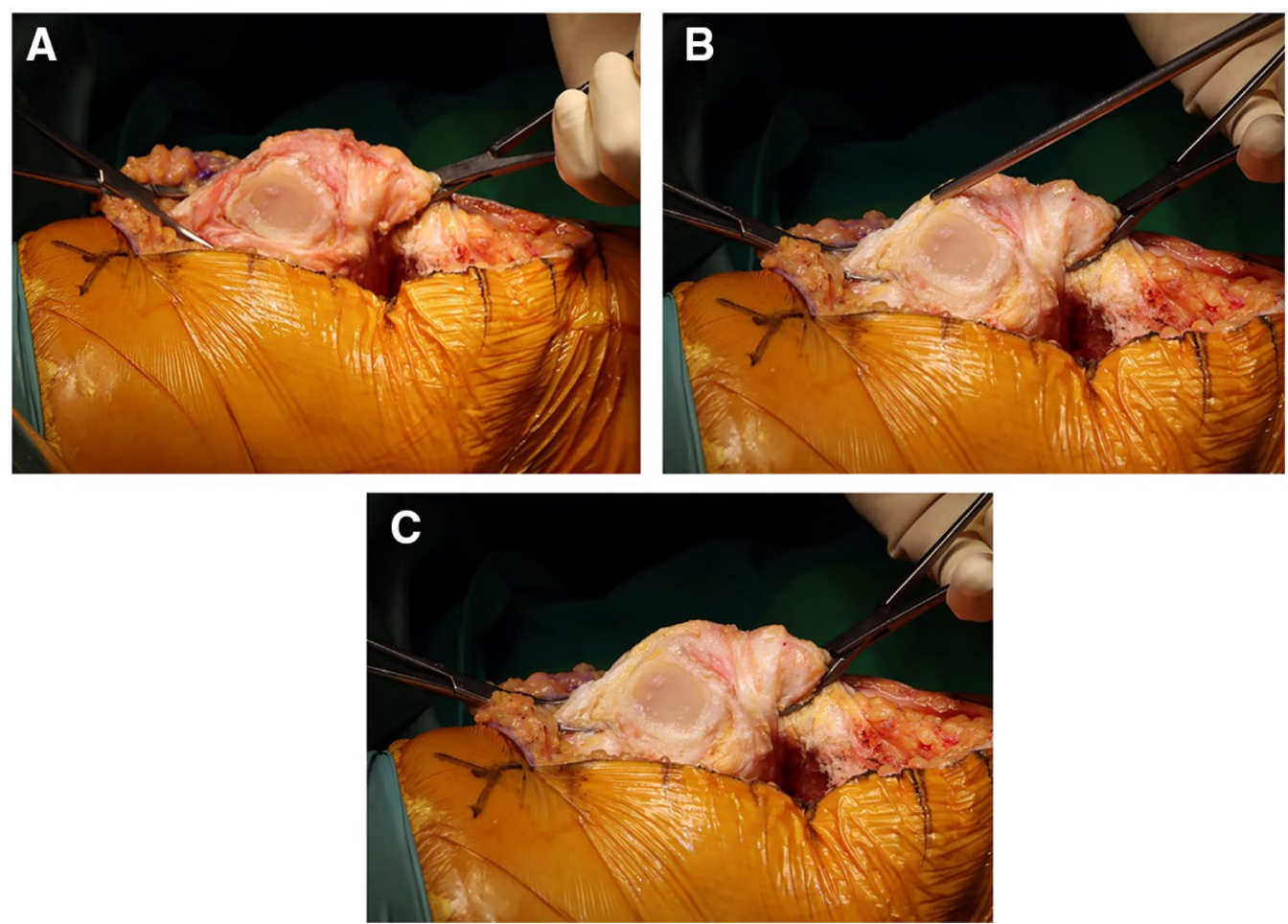

Fig. 3 Synovectomy around the peri-patellar tissue. A Inflamed peri-patellar tissues are observed. B An open synovectomy using an arthroscopy shaver blade is performed. C After synovectomy, yellowish and healthy tissues are exposed

(ESR), and C-reactive protein (CRP), are periodically monitored to confirm a progressive decline in levels [14]. Second-stage re-implantation is performed only when there is sufficient clinical, radiographic, and laboratory evidence supporting eradication of the infection.

\section{Statistical analysis}

The overall analysis was performed with SPSS software (version 25.0, SPSS Inc., Chicago, IL, USA). Comparisons of the mean value of serologic markers between two groups were investigated at each time point using Student's $t$ test with post hoc analysis by Bonferroni's method. The level of statistical significance was set at $p<0.05$.

\section{Results}

A total of 37 knees underwent second-stage revision surgery for the treatment of infected TKA between October 2018 and October 2020. Enrolled patients were followed up from the first-stage surgery [insertion of PROSTALAC (prosthesis of antibiotic-loaded acrylic cement)] [15] to at least 12 months after second-stage re-implantation surgery. This retrospective cohort study was approved by the Institutional Review Board of the authors' hospital.
All surgeries were performed by a single surgeon at a single center. Outcomes of the conventional synovectomy technique using rongeur, electric cautery, and surgical blades (group A [ $n=19$ knees]) were compared with those of the novel synovectomy technique using arthroscopic shaver blade (group B $[n=18$ knees]). Outcome measures included recurrence of infection; serological markers associated with infection, including WBC count, ESR, and CRP, during the follow-up period (first period, between the first- and second-stage surgery; second period, 6 weeks, and 3, 6, and 12 months after secondstage surgery); and the amount of bleeding through the suction drain was investigated.

Demographic characteristics of the patients and outcomes during follow-up are summarized in Table 1. There was no recurrence of infection in either group; however, group B (i.e., novel technique) improved significantly faster in terms of WBC count and CRP level during the first period (Fig. 4). Meanwhile, the amount of bleeding through the suction drain was greater in group $\mathrm{B}$, although the difference was not statistically significant (Table 2). 
Table 1 Patients' demographic characteristics

\begin{tabular}{|c|c|c|c|c|}
\hline Variables & Total $(n=37)$ & Group A $(n=19)$ & Group B $(n=17)$ & $p$ value \\
\hline Mean age $(\text { years })^{a}$ & $72.9(57.0-83.0)$ & $72.1(62.0-81.0)$ & $73.8(57.0-83.0)$ & 0.847 \\
\hline \multicolumn{5}{|l|}{ Sex } \\
\hline Female & $29(78.4 \%)$ & $29(78.4 \%)$ & $29(78.4 \%)$ & \\
\hline Male & $8(21.6 \%)$ & $8(21.6 \%)$ & $8(21.6 \%)$ & \\
\hline BMI $\left(\mathrm{kg} / \mathrm{m}^{2}\right)^{\mathrm{a}}$ & $25.0(19.8-33.8)$ & $25.0(19.8-33.8)$ & $25.0(19.8-33.8)$ & 0.865 \\
\hline Mean F/U period (months) ${ }^{a}$ & $17.5(12.0-37.0)$ & $17.1(12.0-34.0)$ & $17.9(12.0-37.0)$ & 0.641 \\
\hline Diabetes mellitus ${ }^{b}$ & $6 / 37(16.2 \%)$ & $3 / 19(15.8 \%)$ & $3 / 17(17.6 \%)$ & 0.881 \\
\hline
\end{tabular}

$B M I$ body mass index, $F / U$ follow-up

${ }^{a}$ Values are given as means (ranges)

${ }^{\mathrm{b}}$ Values are given as numbers (percentage)

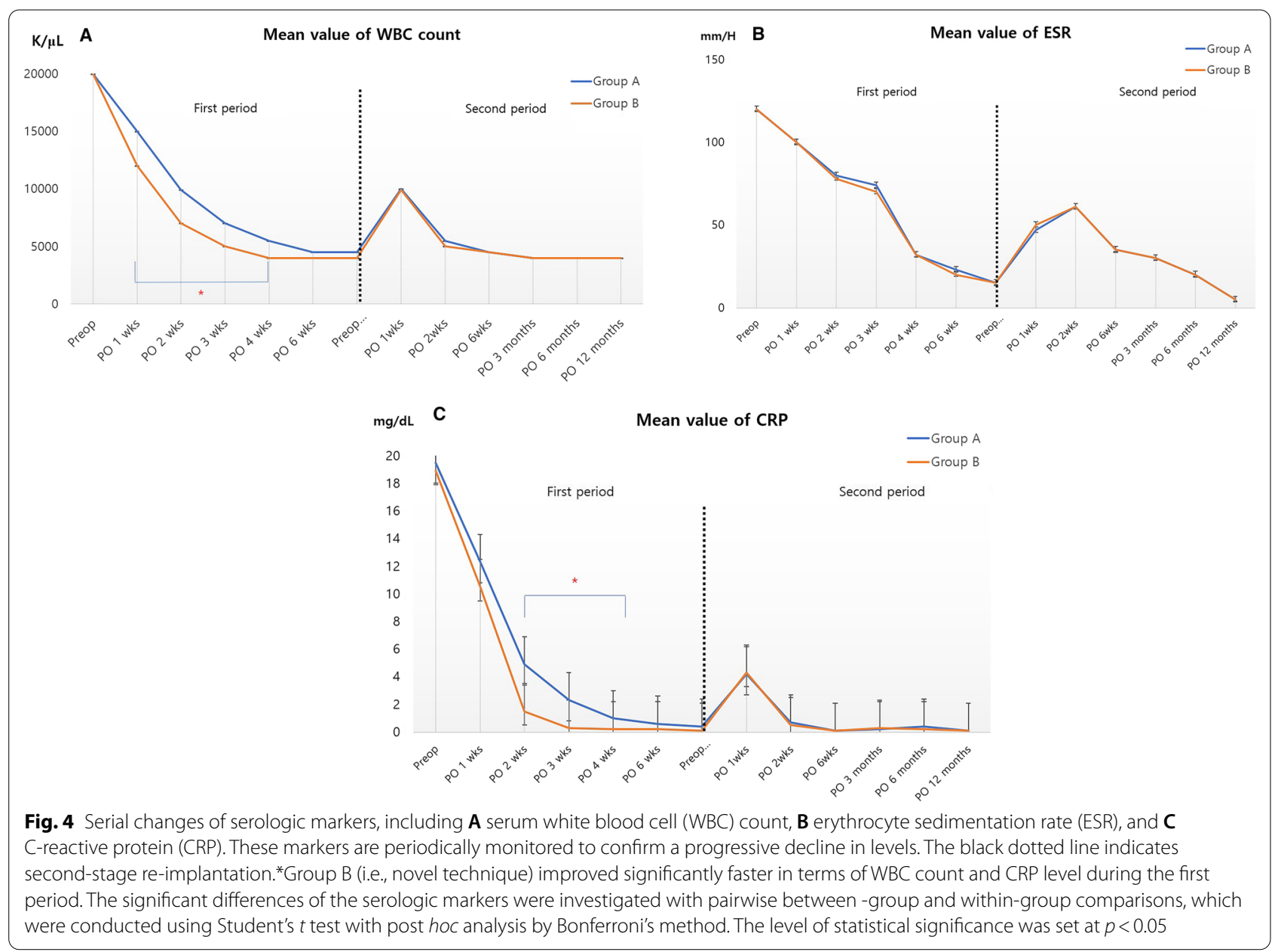

\section{Discussion}

The novel technique described in the present article was prompted by the need to facilitate arthroscopic access to the posterior compartment, which is difficult to access and clean using existing open surgical instruments such as rongeur, electric cautery, and/or surgical blades. We used a shaver blade commonly used in conventional arthroscopic surgery for open revision surgery to treat infected TKA.

Among patients who underwent surgery using this technique, serological markers associated with acute infection, including WBC count and CRP level, improved significantly 
Table 2 Outcomes

\begin{tabular}{|c|c|c|c|c|}
\hline Variables & Total $(n=37)$ & Group A $(n=19)$ & Group B $(n=17)$ & $p$ value \\
\hline Drainage after first-stage surgery $(\mathrm{ml})^{\mathrm{a}}$ & $452.1(80.0-650.0)$ & $450.5(120.0-650.0)$ & $461.3(80.0-620.0)$ & 0.172 \\
\hline Mean duration of IV antibiotics (days) ${ }^{\text {a }}$ & $32.5(24.0-36.0)$ & $33.1(28.0-35.0)$ & $33.1(24.0-35.0)$ & 0.381 \\
\hline Mean duration of oral antibiotics (days) ${ }^{a}$ & $14.7(10.0-21.0)$ & $14.1(10.0-21.0)$ & $15.1(14.0-21.0)$ & 0.632 \\
\hline $\begin{array}{l}\text { Mean duration between 1st- and 2nd-stage } \\
\text { surgery (days) }{ }^{\mathrm{a}}\end{array}$ & $43.5(31.0-91.0)$ & $44.6(42.0-62.0)$ & $42.8(31.0-60.0)$ & 0.109 \\
\hline Recurrence of infection & - & - & - & - \\
\hline
\end{tabular}

The amount of bleed through suction drain was the total amount before removal. At the surgeon's discretion, the drain was removed 3-7 days postoperatively

IV intravenous

${ }^{a}$ Values are given as means (ranges)

faster during the follow-up period because more grossly contaminated or diseased tissue was effectively debrided using a shaver blade. In particular, meticulous debridement of infected tissues around the posterior compartment, which is difficult to access using conventional surgical instruments, was possible using a shaver equipped with a long bar (Fig. 3). Such rapid improvement in laboratory parameters may affect the prognosis of revision surgery for the treatment of infected TKA, such as reducing the possibility of recurrent infection, shortening the period of antibiotic use, and facilitating earlier recovery $[14,16,17]$.

However, ESR decreased with a similar trend in both groups during the follow-up period. Because ESR has a longer half-life than CRP [18], it is more indicative of a persistent, deep-seated joint disease process [16, 19]. Using this novel technique, faster recovery of acute serological markers was achieved in revision surgery for infected TKA, which could help in the rapid improvement of infection.

Another advantage was that precise debridement was possible based on the surgeon's intention. Conventional instruments, such as rongeur, electric cautery, and surgical blade, are unable to meticulously remove infected synovium; moreover, excessive tissue removal could cause bleeding or damage to healthy tissue. On the other hand, when using an arthroscopy shaver blade, it was possible to precisely debride the inflamed layer to reveal the healthy yellowish layer. It enables controlled management of the soft tissue [20]. In addition, this technique can be applied to various surgical scenarios for infected TKA, such as polyethylene exchange, first- and second-stage revision(s), as well as the situation described in this article.

For successful application of this technique, the shaver handpiece must be connected to the suction drain, and saline solution must be continuously supplied by an assistant (Fig. 1). The assistant should manually provide the saline solution using an irrigation spoid during surgery. As with arthroscopic surgery, a slower oscillating mode is usually useful for tissue removal [20]. This enables efficient removal of the debrided (i.e., infected) tissue.
Although this technique is relatively simple and effcient, excessive removal of infected tissue may result in large amounts of bleeding. In the present study, although the difference was not statistically significant, it was found that the amount of bleeding through the suction drain was larger in the group in which the shaver blade was used. This may be considered to be a limitation of using a shaver blade in the reduced field of direct view with the naked eye rather than the magnified screen used in conventional arthroscopy. Therefore, when performing open debridement of infected tissue rather than through arthroscopy, careful attention should be devoted to minimize the risk for unintended tissue or shaver-related damage [20].

Nevertheless, this technique is a novel example of applying arthroscopic instruments to open surgery and was an effective method to overcome the limitations associated with the use of conventional surgical instruments.

\section{Conclusions}

A novel synovectomy technique using an arthroscopy shaver blade yielded favorable outcomes compared with the conventional technique. In particular, it may be an alternative method to improve the approach to the posterior joint space, which is often difficult to access.

\section{Abbreviations}

TKA: Total knee arthroplasty; WBC: Serum white blood cell; ESR: Erythrocyte sedimentation rate; CRP: C-reactive protein; PROSTALAC: Prosthesis of antibiotic-loaded acrylic cement.

\section{Supplementary Information}

The online version contains supplementary material available at https://doi. org/10.1186/s13018-022-03024-5.

Additional file 1: Open synovectomy procedures using an arthroscopic shaver blade. 


\section{Acknowledgements \\ None.}

\section{Authors' contributions}

The following authors have made substantial contributions to the followings: (1) the conception and design of the study were contributed by K.G.B., provision of study materials or patients was contributed by K.G.B., acquisition of data was contributed by K.G.B. and L.I.J., analysis and interpretation of data were contributed by K.G.B. L.I.J., and S.O.J.. (2) Drafting the article was contributed by K.G.B., (3) final approval of the version to be submitted was contributed by K.G.B. and S.O.J. All authors read and approved the final manuscript.

\section{Funding}

This research was supported by the 2020 Yeungnam University Research Grant.

\section{Availability of data and materials}

Not applicable.

\section{Declarations}

\section{Ethics approval and consent to participate}

This retrospective cohort study was approved by the Institutional Review Board of the authors' hospital (YUMC 2021-11-018). Informed consent was waived by the Institutional Review Board of the Ethics Committee of Yeungnam University College of Medicine and Yeungnam University Medical Center.

\section{Consent for publication}

All authors read and approved the final manuscript and gave consent for publication. The content of the manuscript has not been published, or submitted for publication elsewhere.

\section{Competing interests}

The authors declare that they have no competing interests.

\section{Author details}

'Present Address: Department of Orthopedic Surgery, Yeungnam University College of Medicine, 170 Hyeonchung-ro Nam-gu, Daegu 42415, Republic of Korea. ${ }^{2}$ Department of Orthopedic Surgery, Yeungnam University Medical Center, 170 Hyeonchung-ro Nam-gu, Daegu 42415, Republic of Korea.

Received: 29 December 2021 Accepted: 17 February 2022 Published online: 03 March 2022

\section{References}

1. Schmitt DR, Killen C, Murphy M, Perry M, Romano J, Brown N. The impact of antibiotic-loaded bone cement on antibiotic resistance in periprosthetic knee infections. Clin Orthop Surg. 2020;12(3):318-23.

2. Son WS, Shon O-J, Lee D-C, Park S-J, Yang HS. Efficacy of open debridement and polyethylene exchange in strictly selected patients with infection after total knee arthroplasty. Knee Surg Relat Res. 2017;29(3):172.

3. Ha C-W. Treatment of infected total knee arthroplasty. Knee Surg Relat Res. 2017;29(3):153.

4. Kurtz SM, Lau E, Schmier J, Ong KL, Zhao K, Parvizi J. Infection burden for hip and knee arthroplasty in the United States. J Arthroplasty. 2008;23(7):984-91.

5. Mittal Y, Fehring TK, Hanssen A, Marculescu C, Odum SM, Osmon D. Twostage reimplantation for periprosthetic knee infection involving resistant organisms. J Bone Joint Surg Am. 2007;89(6):1227-31.

6. Joulie D, Girard J, Mares O, Beltrand E, Legout L, Dezeque H, et al. Factors governing the healing of Staphylococcus aureus infections following hip and knee prosthesis implantation: a retrospective study of 95 patients. Orthop Traumatol Surg Res. 2011;97(7):685-92.

7. Quinn J, Jones P, Randle R. Clinical outcomes following revision total knee arthroplasty: minimum 2-Year follow-up. Clin Orthop Surg. 2022;14(1):69-75.
8. Li AE, Sneag DB, Greditzer HG IV, Johnson CC, Miller TT, Potter HG. Total knee arthroplasty: diagnostic accuracy of patterns of synovitis at MR imaging. Radiol. 2016;281(2):499-506.

9. Potter HG, Foo LF. Magnetic resonance imaging of joint arthroplasty. Orthop Clin N Am. 2006:37(3):361-73.

10. Plodkowski AJ, Hayter CL, Miller TT, Nguyen JT, Potter HG. Lamellated hyperintense synovitis: potential MR imaging sign of an infected knee arthroplasty. Radiol. 2013;266(1):256-60.

11. Lizaur-Utrilla A, Gonzalez-Parreño S, Gil-Guillen V, Lopez-Prats F. Debridement with prosthesis retention and antibiotherapy vs two-stage revision for periprosthetic knee infection within 3 months after arthroplasty: a case-control study. Clin Microbiol Infect. 2015;21(9):851e11-e17.

12. Parvizi J, Tan TL, Goswami K, Higuera C, Della Valle C, Chen AF, et al. The 2018 definition of periprosthetic hip and knee infection: an evidencebased and validated criteria. J Arthroplasty. 2018;33(5):1309.e2-14.e2.

13. Goswami K, Stevenson KL, Parvizi J. Intraoperative and postoperative infection prevention. J Arthroplasty. 2020;35(3):S2-8.

14. Tohidi M, Rudan JF. Diagnosing the infected total knee arthroplasty. Evid Based Orthop. 2021;66:315-9.

15. Gooding CR, Masri BA, Duncan CP, Greidanus NV, Garbuz DS. Durable infection control and function with the PROSTALAC spacer in twostage revision for infected knee arthroplasty. Clin Orthop Relat Res. 2011;469(4):985-93.

16. Klare CM, Fortney TA, Kahng PW, Cox AP, Keeney BJ, Moschetti WE. Prognostic factors for success after irrigation and debridement with modular component exchange for infected total knee arthroplasty. J Arthroplasty. 2018;33(7):2240-5.

17. Litao MKS, Kamat D. Erythrocyte sedimentation rate and C-reactive protein: how best to use them in clinical practice. Pediatr Ann. 2014;43(10):417-20.

18. Costenbader K, Chibnik L, Schur P. Discordance between erythrocyte sedimentation rate and C-reactive protein measurements: clinical significance. Clin Exp Rheumatol. 2007;25(5):746.

19. Feldman M, Aziz B, Kang GN, Opondo MA, Belz RK, Sellers C. C-reactive protein and erythrocyte sedimentation rate discordance: frequency and causes in adults. Transl Res. 2013;161(1):37-43.

20. Singh S, Tavakkolizadeh A, Arya A, Compson J. Arthroscopic powered instruments: a review of shavers and burrs. Orthop Trauma. 2009;23(5):357-61.

\section{Publisher's Note}

Springer Nature remains neutral with regard to jurisdictional claims in published maps and institutional affiliations.

Ready to submit your research? Choose BMC and benefit from

- fast, convenient online submission

- thorough peer review by experienced researchers in your field

- rapid publication on acceptance

- support for research data, including large and complex data types

- gold Open Access which fosters wider collaboration and increased citations

- maximum visibility for your research: over $100 \mathrm{M}$ website views per year

At BMC, research is always in progress.

Learn more biomedcentral.com/submissions 